Thiophene-containing products of the Ugi reaction in an oxidation-triggered IMDA/aromatization cascade: a simple access to 3-oxoisoindolines

Mikhail Krasavin* and Vadislav Parchinsky

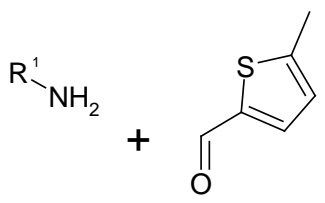

5 examples

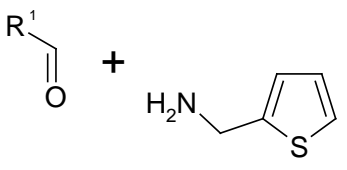

5 examples
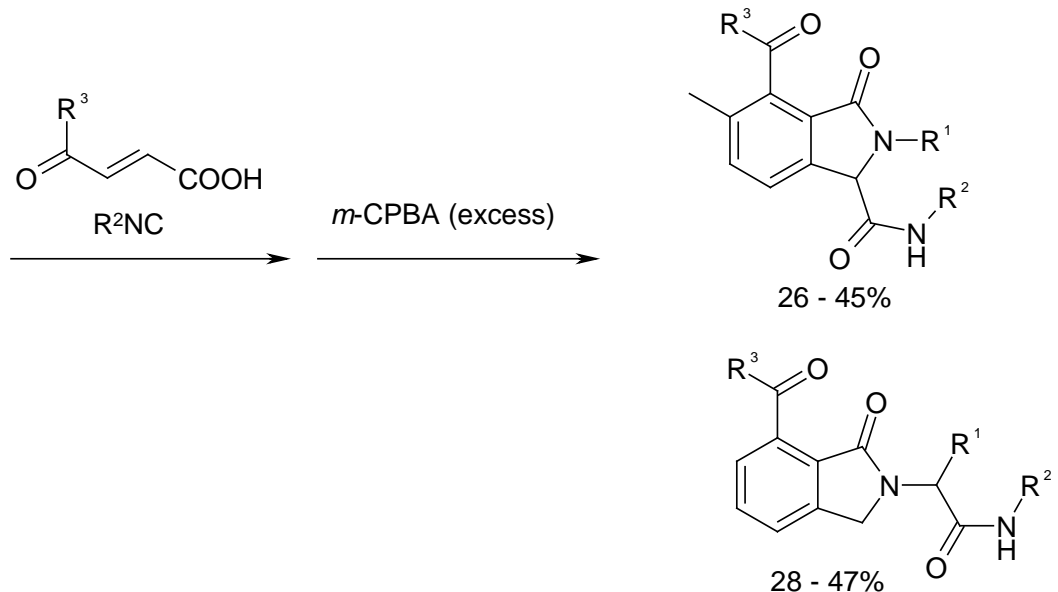


\section{Thiophene-containing products of the Ugi reaction in an oxidation-triggered IMDA/aromatization cascade: a simple access to 3-oxoisoindolines}

Mikhail Krasavin ${ }^{a, b}$ and Vadislav Parchinsky ${ }^{b}$

a Science and Education Center “Innovative Research”, Yaroslavl State Pedagogical University, 150000, Russia

${ }^{b}$ Chemical Diversity Research Institute, 2a Rabochaya St., Khimki, Moscow Reg., 141400, Russia

*Corresponding author, e-mail: myk@chemdiv.com, phone: +7(495)995-4944, fax: +7(495)6269780.

Abstract - A novel approach to skeletally diverse 3-oxoisoindolines has been developed which includes preparation of Ugi adducts containing thiophene and fumaric acid residues. When treated with excess $m$-CPBA at room temperature, these precursors undergo a simple oxidative cycloaddition/aromatization transformation and the corresponding 3-oxoisoindoline products are isolated in fair chemical yield over two steps. The second step is thought to include $S$ oxidation/IMDA/S-oxidation/ $\mathrm{SO}_{2}$ extrusion/aromatization events.

Keywords: isocyanide-based multicomponent reactions, post-Ugi transformation, intramolecular Diels-Alder reaction, oxidative cycloaddition, thiophene oxidation, sulfur dioxide extrusion, aromatization.

One of the prominent features of the Ugi multicomponent reaction (U-MCR) ${ }^{1}$ is its remarkably broad scope with regard to the choice of reagents. When the reagents for this fourcomponent process are selected so as to include both a diene and a dienophile, a product is obtained which can undergo an intramolecular Diels-Alder (IMDA) reaction. The latter may be energetically favored so as to occur immediately after the Ugi event, or may require additional activation (e.g., thermal). The utility of the IMDA for post-Ugi modification ${ }^{2}$ to create additional product complexity was demonstrated, for instance, in the work of Schreiber. ${ }^{3}$ In this example of diversity-oriented synthesis, a 'complex enough' 7-oxabicyclo[2.2.1]hept-2-ene Ugi/IMDA product 1 gave rise to an even more complex and skeletally intriguing 7,5,5,7 polycyclic compound. In another notable example disclosed by Paulvannan, an Ugi reaction product containing an activated pyrrole moiety and an electron-deficient alkyne underwent a similar reverse electron-demand IMDA on heating. ${ }^{4}$ The final product in this case was the 3- 
oxoisoindoline $\mathbf{2}$ formed as a result of a simple aromatization of the intermediate IMDA product (Scheme 1).

Previously, we reported ${ }^{5}$ that aromatization of Ugi/IMDA products related to $\mathbf{1}$, aimed at 3oxoisoindolines, was less straightforward. In strong acidic medium at high temperatures (typical conditions for dehydrative aromatization of 7-oxabicyclo[2.2.1]hept-2-enes ${ }^{6}$ ), an unexpected rearrangement was observed, while the desired aromatization could be achieved in one case with catalytic $\mathrm{BF}_{3} \cdot \mathrm{OEt}_{2}$ under microwave irradiation (Scheme 2). This approach, however, suffered from limited scope and therefore we have sought to develop an alternative and, preferably, more chemically benign (in view of functional group tolerance) strategy based on the Ugi/IMDA/aromatization sequence.

Among five-membered aromatic heterocycles, thiophene is known to be least reactive as a diene. ${ }^{7}$ Its two oxidized forms - thiophene-S-oxide and thiophene-S,S-dioxide - are more reactive dienes; the latter, however, often requires additional activation. ${ }^{8}$ Thiophene-S-oxide can be regarded as an intermediate en route to thiophene-S,S-dioxide and is not isolable, unless special precautions (such as carefully controlled reaction temperature ${ }^{9}$ or stabilization of the monoxide form toward further oxidation by Lewis acid additives ${ }^{10}$ ) are taken.

As a highly reactive species, thiophene-S-oxide can be trapped if the thiophene oxidation is performed in the presence of a dienophile. ${ }^{11}$ The resulting adduct 3 cannot be aromatized efficiently and requires further chemical (e.g., $\mathrm{KMnO}_{4}$, under PTC conditions; $m$-CPBA ${ }^{12}$ ) or electrochemical ${ }^{13}$ oxidation into 4; the latter aromatizes via extrusion of sulfur dioxide (followed by another two-electron oxidation) to give 5 (Scheme 3). Progression of the thiophene species through the oxidative cycloaddition will be hampered if the oxidation and the dienophile trapping of thiophene-S-oxide are in competition [i. e. if $\mathrm{k}_{1}(\mathrm{DA}) \approx \mathrm{k}_{2}(\mathrm{ox})$ ]: once formed, thiophene-S,S-dioxide is essentially lost to the Diels-Alder reaction, unless additional activation is applied (vide supra). We reasoned that for an energetically favored (compared to an intermolecular process) intramolecular cycloaddition, $\mathrm{k}_{1}(\mathrm{DA})$ would be increased and a suitable precursor (containing both a thiophene moiety and an electron-deficient olefin) would be effectively progressed through the oxidative cycloaddition route.

Two series of thiophene-containing precursors $\mathbf{6}$ and $\mathbf{7}$ were synthesized via the Ugi reaction in methanol from either 5-methylthiophene-2-carboxaldehyde or 2aminomethylthiophene, respectively. Without further purification, ${ }^{14}$ the crude product $\mathbf{6}$ or $\mathbf{7}$ was treated with excess (6-7 equiv.) of m-chloroperbenzoic acid (m-CPBA) in $\mathrm{CH}_{2} \mathrm{Cl}_{2}$ at room temperature. After 24 hours, the Ugi dipeptoids 6 or $\mathbf{7}$ were no longer present in the reaction 
mixture, as was evident from LC-MS analysis, and the main product peak in each case displayed an $\mathrm{m} / \mathrm{z}$ value corresponding to the 3-oxoisoindolines $\mathbf{8}$ or $\mathbf{9}$, respectively (Scheme 4), along with a number of unidentified by-products. Following aqueous work-up of the reaction mixture (involving quenching of unreacted $m$-CPBA with $\mathrm{Na}_{2} \mathrm{SO}_{3}$ solution), the 3-oxoisoindolines 8 and 9 were isolated in fair overall yields (from the Ugi reaction precursors) using flash column chromatography (Table 1). Alternative oxidants (such as Oxone ${ }^{\circledR}$, biphasic conditions, or peracetic acid) were also found to trigger the cycloaddition, albeit leading to much lower $(<10 \%)$ yields of the target 3-oxoisoindolines.

Notably, despite the relatively low chemical yield, no unreactive (with respect to IMDA) thiophene-S,S-dioxides 10 or 11 (Figure 1) were detected by LC-MS analysis in the crude reaction mixture following the oxidative cycloaddition step. This, in our view, exemplified the fundamental correctness of the reasoning used in the reaction design. From a mechanistic perspective, the transformation of $\mathbf{6}$ and $\mathbf{7}$ into $\mathbf{8}$ and $\mathbf{9}$, respectively, is thought to include $S$ oxidation/IMDA/S-oxidation/ $\mathrm{SO}_{2}$ extrusion/aromatization events (Scheme 3).

The described assembly of two skeletally diverse series of 3-oxoisoindolines involves two simple chemical operations (and only one purification) and is extremely atom economic: indeed, all the Ugi reaction components were incorporated predictably into the structure of the final product, with loss of water via condensation in the Ugi step and extrusion of sulfur dioxide in the cycloaddition/aromatization step. The excess oxidant was removed completely on aqueous workup and chromatographic separation of the less polar target compounds from the more polar byproducts was quite straightforward. These 3-oxoisoindolines represent a relatively novel class of drug-like compounds recently discovered by Abbott as inhibitors of poly(ADP-ribose) polymerase. $^{15}$

Synthesis of 8 or 9; typical procedure (10 mmol scale, ambient atmosphere): Equimolar amounts of an aldehyde and an amine in $\mathrm{MeOH}(10 \mathrm{~mL})$ were stirred at $\mathrm{r}$. t. for $1 \mathrm{~h}$. Isocyanide (1 equiv.) was added followed by a carboxylic acid (1 equiv.) and stirring was continued for 1824 h. In most cases (except $6 \mathbf{d}$ and 7c-e) the product precipitated from the reaction mixture and was separated (at least $85 \%$ pure) by filtration. Otherwise, the mixture was concentrated, the residue dissolved in $\mathrm{CH}_{2} \mathrm{Cl}_{2}(50 \mathrm{~mL})$ and washed with $10 \%$ aq. $\mathrm{HCl}(50 \mathrm{~mL}), 10 \%$ aq. $\mathrm{NaHCO}_{3}$ (50 mL) and $\mathrm{H}_{2} \mathrm{O}(2 \times 25 \mathrm{~mL})$. The organic layer was dried over anhydrous $\mathrm{MgSO}_{4}$, filtered and concentrated to provide the crude Ugi reaction product (at least $80 \%$ pure). This material was 
dissolved in $\mathrm{CH}_{2} \mathrm{Cl}_{2}$ (40 mL), treated with m-CPBA (7-8 equiv.) and stirred at r.t. for 24 h. Concentrated aq. $\mathrm{Na}_{2} \mathrm{SO}_{3}$ (10 equiv.) was added and the resulting biphasic mixture was stirred vigorously for $1 \mathrm{~h}$. The aqueous layer was separated and the organic layer washed with sat. aq. $\mathrm{NaHCO}_{3}$ (3 x $20 \mathrm{~mL}$ ), to ensure complete removal of $m$-CPBA, and with $\mathrm{H}_{2} \mathrm{O}$ (25 mL). Drying over anhydrous $\mathrm{MgSO}_{4}$, filtration, and evaporation of the solvent afforded the crude product. The target 3-oxoisoindolines were isolated by flash column chromatography on silica using an appropriate gradient of EtOAc in hexanes as eluent.

8d: beige solid, $\mathrm{mp}=167-169{ }^{\circ} \mathrm{C} .{ }^{1} \mathrm{H}$ NMR $\left(\mathrm{DMSO}-\mathrm{d}_{6}, 400 \mathrm{MHz}\right) \delta 8.92(\mathrm{~m}, 1 \mathrm{H}), 7.37$ (dd, $J=$ 17.6, 7.7 Hz, 2H), 7.17 (d, $J=8.2 \mathrm{~Hz}, 2 \mathrm{H}), 6.84$ (d, $J=8.2 \mathrm{~Hz}, 2 \mathrm{H}), 5.23$ (m, 1H), 5.16 (s, 1H), 4.24 (d, $J=4.8 \mathrm{~Hz}, 2 \mathrm{H}), 3.80$ (m, 1H), 3.74 (s, 3H), 2.30 (s, 3H), 1.46-1.87 (m, 6H), 1.34 (br s, $6 \mathrm{H}), 1.20-1.43$ (m, 3H), 0.99-1.14 (m, 1H). ${ }^{13} \mathrm{C}$ NMR (DMSO-d $\left.d_{6}, 100 \mathrm{MHz}\right) \delta 167.6,166.2$, 166.1, 158.3, 139.7, 133.8, 132.8, 130.5, 130.0, 128.7, 128.4, 122.1, 113.4, 95.4, 68.2, 61.3, 54.8, 52.3, 42.0, 30.1, 29.9, 25.3, 25.2, 24.9, 21.4, 21.3, 17.7. Anal. Calcd for $\mathrm{C}_{28} \mathrm{H}_{34} \mathrm{~N}_{2} \mathrm{O}_{5}$ : C, 70.27; H, 7.16; N, 5.85. Found: C, 70.35; H, 7.24; N, 5.77.

9b: white solid, $\mathrm{mp}=201{ }^{\circ} \mathrm{C}$ (dec.). ${ }^{1} \mathrm{H}$ NMR $\left(\mathrm{CDCl}_{3}, 400 \mathrm{MHz}\right) \delta 12.91$ (s, 1H), $8.59(\mathrm{~d}, J=$ $7.7 \mathrm{~Hz}, 1 \mathrm{H}), 7.66$ (dt, $\left.J_{d}=14.3 \mathrm{~Hz}, J_{t}=7.7 \mathrm{~Hz}, 2 \mathrm{H}\right), 7.41-7.49(\mathrm{~m}, 6 \mathrm{H}), 7.19-7.28(\mathrm{~m}, 2 \mathrm{H}), 7.11$ (t, $J=7.1 \mathrm{~Hz}, 1 \mathrm{H}), 6.16$ (br s, 1H), 6.14 (s, 1H), 5.01 (d, $J=17.9 \mathrm{~Hz}, 1 \mathrm{H}), 4.05$ (d, $J=17.9 \mathrm{~Hz}$, 1H), 3.98 (m, 1H), 2.40 (s, 3H), 1.85-1.95 (m, 2H), 1.30-1.65 (m, 10H). ${ }^{13} \mathrm{C}$ NMR (CDCl, 100 MHz) $\delta 169.4,167.4,162.6,143.5,136.5,134.6,132.8,132.3,132.2,131.8,130.4,129.1,128.9$, 128.2, 126.1, 125.8, 125.5, 125.4, 59.0, 51.1, 48.3, 34.7, 34.6, 27.8, 27.7, 24.0, 18.5. Anal. Calcd for $\mathrm{C}_{31} \mathrm{H}_{33} \mathrm{~N}_{3} \mathrm{O}_{3}$ : C, 75.13; $\mathrm{H}, 6.71 ; \mathrm{N}, 8.48$. Found: C, 75.13; H, 6.67; N, 8.42.

Acknowledgement. This research was supported by the Federal Agency for Science and Innovation (Russian Federation Government Contract 02.740.11.0092).

Supporting Information Available: Characterization data for compounds 8a-e and 9a-e.

\section{References and notes.}

1. Dömling, A.; Ugi, I. Angew. Chem. Int. Ed. 2000, 39, 3168-3210.

2. (a) Akritopoulou-Zanze, I.; Djuric, S. W. Heterocycles 2007, 73, 125-147 (comprehensive review); (b) Wu, J.; Yong, J.; Wei-Min, D. Synlett 2009, 1162-1166; (c) Hulme, C.; Chapetta, S.; Griffith, C.; Lee, Y.-S.; Dietrich, J. Tetrahedron Lett. 2009, 50, 1939-1942; (d) Erb, W.; 
Neuville, L.; Zhu, J. J. Org. Chem. 2009, 74, 3109-3115; (e) Basso, A.; Banfi, L.; Guanti, G.; Riva, R. Org. Biomol. Chem. 2009, 7, 253-258.

3. (a) Lee, D.; Sello, J. K.; Schreiber, S. L. Org. Lett. 2000, 2, 709-712; (b) Sello, J. K.; Andreana, P. R.; Lee, D.; Schreiber, S. L. Org. Lett. 2003, 5, 4125-4127.

4. Paulvannan, K. J. Org. Chem. 2004, 69, 1207-1214.

5. Ilyin, A.; Kysil, V.; Krasavin, M.; Kurashvili, I.; Ivachtchenko, A. V. J. Org. Chem. 2006, 71, 95449547.

6. (a) Varlamov, A. V.; Sidorenko, N. V.; Zubkov, F. I.; Chernyshev, A. I. Khim. Geterotsikl. Soedin. 2002, 79, 556-566; (b) Zubkov, F. I.; Boltukhina, E. V.; Krapivko, A. P.; Varlamov, A. V. Khim. Geterotsikl. Soedin. 2003, 80, 1738-1740; (c) Varlamov, A. V.; Boltukhina, E. W.; Zubkov, F. I.; Sidorenko, N. V.; Chernyshev, A. I.; Grudinin, D. G. Khim. Geterotsikl. Soedin. 2004, 81, 27-33.

7. (a) Jursic, B. S. J. Heterocycl. Chem. 1995, 32, 1445-1455. (b) For a rare example of a lowyielding IMDA reaction involving a non-oxidized thiophene moiety, see: Santra, S.; Andreana, P. R. Org. Lett. 2007, 9, 5035-5038.

8. Kang, J.; Santamaria, J.; Hilmersson, G.; Rebek, J. J. Am. Chem. Soc. 1998, 120, 73897390.

9. Zeng, H.; Eguchi, S. Synlett 1997, 175-176.

10. Li, Y.; Thiemann, T.; Sawada, T.; Mataka, S.; Tashiro,, M. J. Org. Chem. 1997, 62, 79627963.

11. Naperstkow, A. M.; Macaulay, J. B.; Newlands, M. J.; Fallis, A. G. Tetrahedron Lett. 1989, 30, 5077-5080.

12. Dongol, K. G.; Mataka, S.; Thiemann, T. J. Chem. Res. (S) 2003, 527-528.

13. Thiemann, T.; Sa e Melo, M. L.; Campos Neves, A. S.; Li, Y.; Mataka, S.; Tashiro, M.; Geißler, U.; Walton, D. J. Chem. Res. (S) 1998, 346-347.

14. Performing the oxidative transformation of purified Ugi reaction products into the respective 3-oxoisoindolines did not improve the yields of the latter, as was demonstrated for the following compound. 6c: $\mathrm{mp}=183{ }^{\circ} \mathrm{C}$ (dec.). ${ }^{1} \mathrm{H}$ NMR (DMSO- $\left.d_{6}, 400 \mathrm{MHz}\right) \delta 9.59(\mathrm{~s}, 1 \mathrm{H})$, 8.33 (t, $J=6.2 \mathrm{~Hz}, 1 \mathrm{H}), 7.34-7.42$ (m, 2H), $7.06-7.21$ (m, 5H), 6.85 (d, $J=3.2 \mathrm{~Hz}, 1 \mathrm{H}), 6.74$ 
(d, $J=11.9 \mathrm{~Hz}, 1 \mathrm{H}), 6.61$ (m, 1H), 6.36 (d, $J=11.9 \mathrm{~Hz}, 1 \mathrm{H}), 5.92$ (s, 1H), 4.25 (d, $J=6.0 \mathrm{~Hz}$, 2H), 2.59 (m, 1H), 2.40 (s, 3H), 2.20 (s, 3H), 0.81-0.89 (m, 1H), 0.54-0.77 (m, 3H). ${ }^{13} \mathrm{C}$ NMR $\left(\mathrm{DMSO}_{6}, 100 \mathrm{MHz}\right) \delta 169.4,167.9,162.8,160.1\left(\mathrm{~d}, J_{C-F}=249.6 \mathrm{~Hz}\right), 139.1,136.5\left(\mathrm{~d}, J_{C-F}=\right.$ $3.4 \mathrm{~Hz}$ ), 135.2, 134.9, 131.0, 129.3 (d, $\left.J_{C-F}=70.0 \mathrm{~Hz}\right), 127.3,127.2,125.3,124.9$, 124.6 (d, $J_{C-F}$ = 75.2 Hz), 123.5, 118.7 (d, $\left.J_{C-F}=17.8 \mathrm{~Hz}\right), 115.7$ (d, $J_{C-F}=20.7 \mathrm{~Hz}$ ), 95.1, 58.8, 41.2, 29.0, 17.1, 14.1, 8.4, 7.5. Anal. Calcd for $\mathrm{C}_{28} \mathrm{H}_{27} \mathrm{ClFN}_{3} \mathrm{O}_{3} \mathrm{~S}$ : C, 62.27; H, 5.04; N, 7.78. Found: C, 62.36; H, 5.12; N, 7.85 .

15. Gandhi, V. B.; Luo, Y.; Liu, X.; Shi, Y.; Klinghofer, V.; Johnson, E. F.; Park, C.; Giranda, V. L.; Penning, T. D.; Zhu, G.-D. Bioorg. Med. Chem. Lett. 2010, 20, 1023-1026.

Scheme 1. Examples of complexity-generating Ugi/IMDA tandem processes.
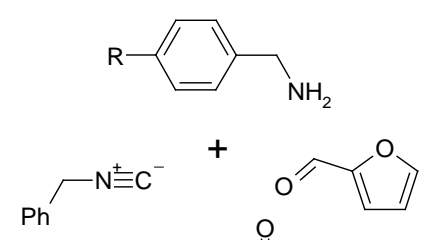<smiles>O=C(O)/C=C/C(=O)NCBr</smiles><smiles>[C-]#[N+]Cc1ccccc1</smiles>

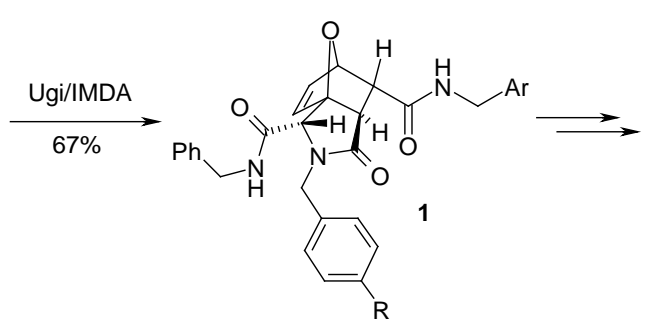<smiles>C#CC(=O)N(Cc1ccccc1)C(C(=O)NCc1ccccc1)c1cccn1S(C)(=O)=O</smiles>

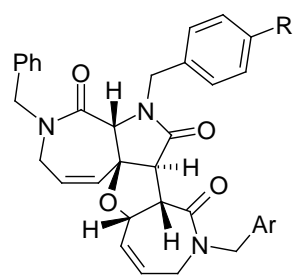

Ref. 3

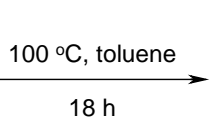

$18 \mathrm{~h}$

Ref. 4<smiles></smiles>

Scheme 2. Aromatization of Ugi/IMDA-derived 7-oxabicyclo[2.2.1]hept-2-enes and their unexpected rearrangement in phosphoric acid. ${ }^{5}$
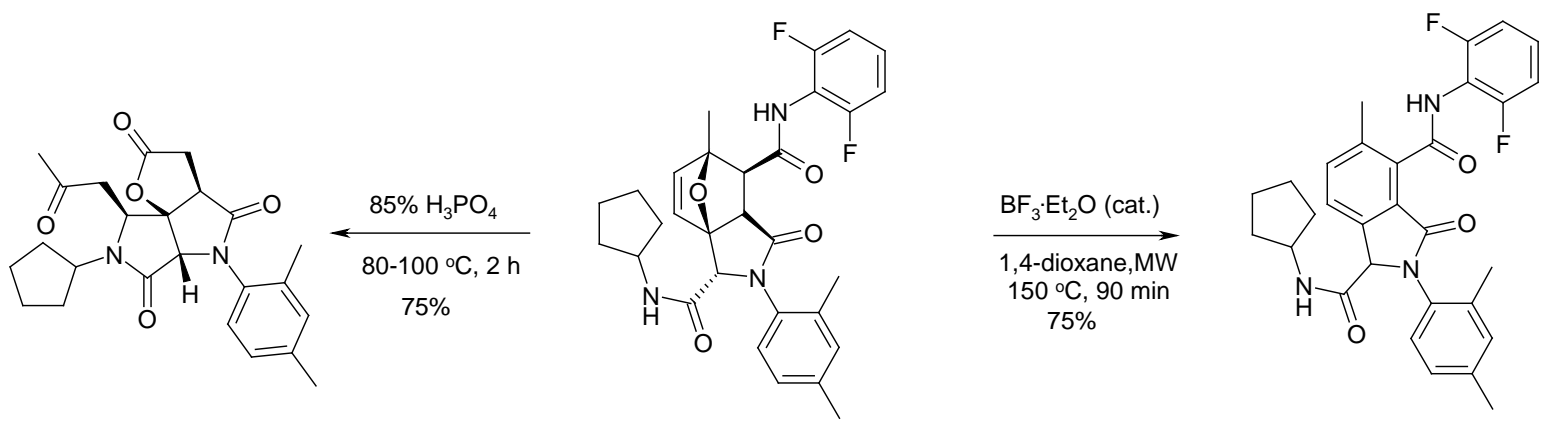
Scheme 3. Oxidized forms of thiophene, their interaction with dienophiles, and aromatization of the Diels-Alder adducts.

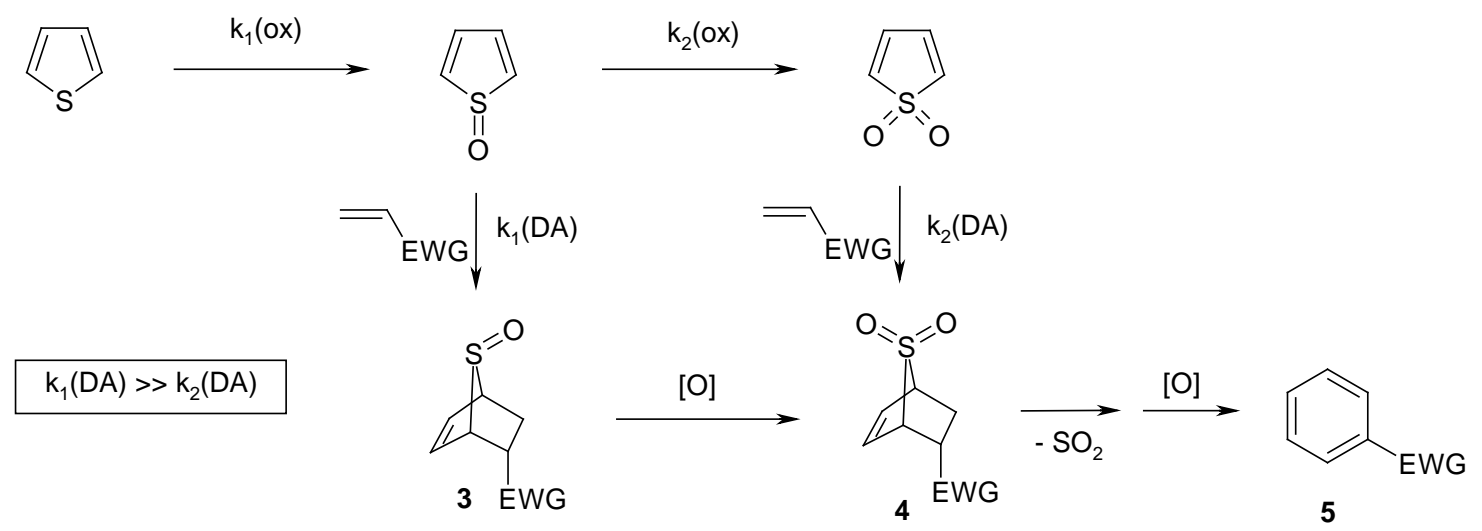

Scheme 4. Preparation of thiophene-containing precursors via the Ugi reaction and their transformation into 3-oxoisoindolines by treatment with $m$-CPBA.

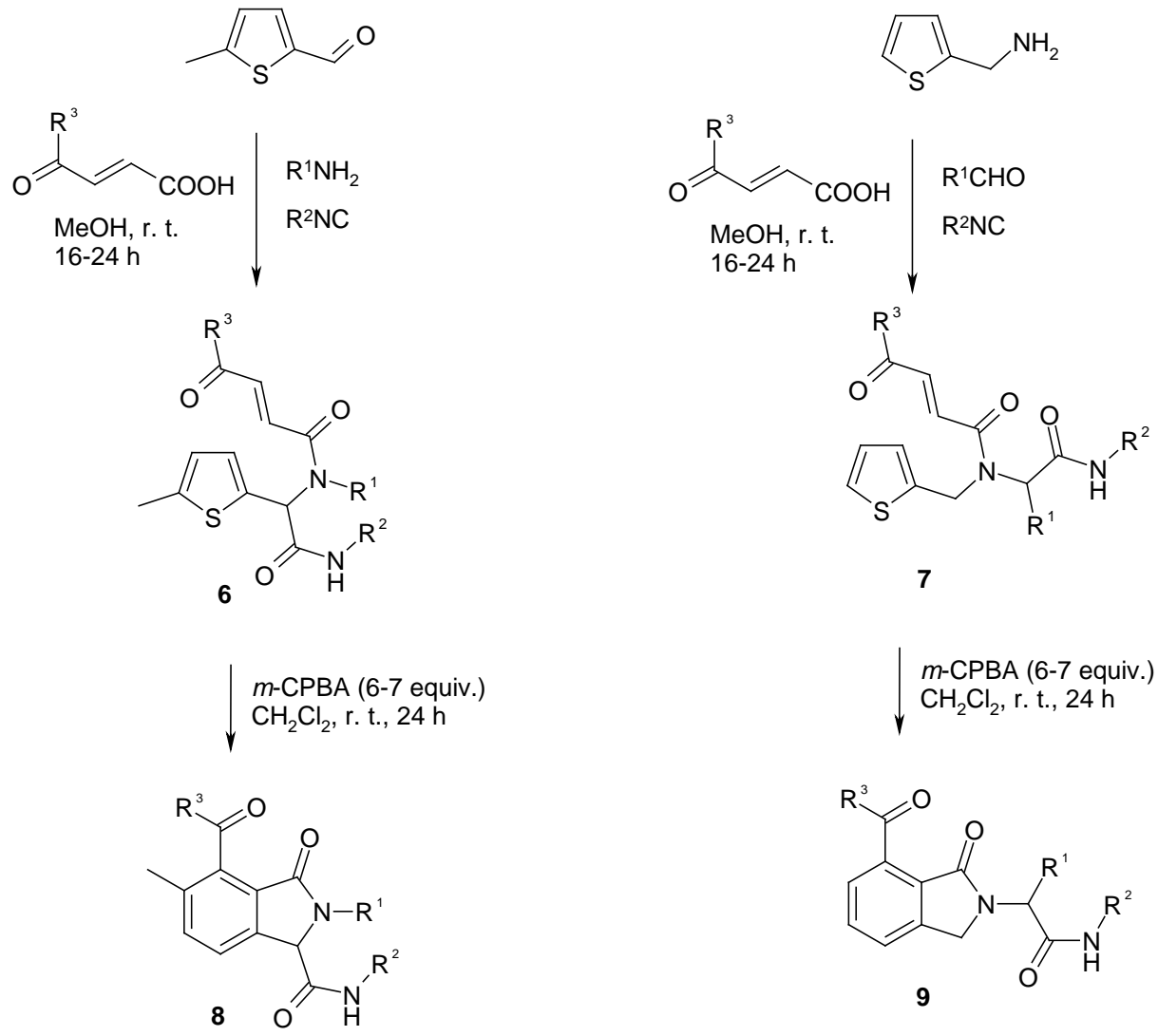

Figure 1. Structures of the unreactive thiophene-S,S-dioxides (not observed).

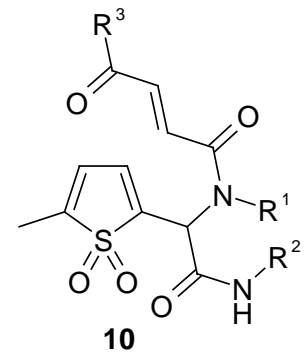<smiles>[R]NC(=O)C([R])N(CC1=CC=CS1(=O)=O)C(=O)/C=C/C([R])=O</smiles>

11 
Table 1. 3-Oxoisoindolines 8 and 9 prepared in this work from the Ugi reaction products 6 and 7, respectively.

\begin{tabular}{|c|c|c|c|c|c|c|c|}
\hline \multirow[b]{2}{*}{ Entry } & \multirow[b]{2}{*}{$\mathrm{R}^{1}$} & \multirow[b]{2}{*}{$\mathrm{R}^{2}$} & \multirow[b]{2}{*}{$\mathrm{R}^{3}$} & \multicolumn{2}{|c|}{$1^{\text {st }}$ step } & \multicolumn{2}{|c|}{$2^{\text {nd }}$ step } \\
\hline & & & & Product & $\begin{array}{c}\mathrm{LC}-\mathrm{MS} \\
{\left[\mathrm{M}+\mathrm{H}^{+}\right]} \\
m / \mathrm{z}\end{array}$ & Product & $\begin{array}{c}\text { Yield, } \\
\%\end{array}$ \\
\hline 1 & & & & $6 a$ & 562.6 & $8 a$ & 33 \\
\hline 2 & & & & $6 b$ & 579.2 & $8 b$ & 28 \\
\hline 3 & & & & $6 c$ & 541.3 & 8c & 45 \\
\hline 4 & & & & 6d & 513.7 & 8d & 29 \\
\hline 5 & MeO & & & $6 e$ & 574.6 & $8 e$ & 26 \\
\hline 6 & & & & $7 a$ & 574.8 & $9 a$ & 47 \\
\hline 7 & & & & $7 \mathbf{b}$ & 530.5 & $9 b$ & 38 \\
\hline 8 & & & & 7c & 530.1 & 9c & 28 \\
\hline 9 & & & & 7d & 535.6 & 9d & 34 \\
\hline 10 & & & - & $7 e$ & 521.4 & $9 e$ & 39 \\
\hline
\end{tabular}

